\title{
Cross-cultural adaptation of the Filial Responsibility protocol for use in Brazil
}

\author{
Adaptação transcultural do protocolo Filial Responsibility para uso no Brasil \\ Adaptación transcultural del protocolo Filial Responsibility para uso en Brasil
}

\section{Marines Aires', Fernanda Laís Fengler Dal Pizzol', Duane Mocellin', Idiane Rosset', Eliane Pinheiro de Morais', Lisiane Manganelli Girardi Paskulin'}

\author{
' Universidade Federal do Rio Grande do Sul, Nursing School, Postgraduate Program in Nursing. Porto Alegre, \\ Rio Grande do Sul, Brazil.
}

To cite this article:

Aires M, Dal Pizzol FLF, Mocellin D, Rosset I, Morais EP, Paskulin LMG. Cross-cultural adaptation of the Filial Responsibility protocol for use in Brazil. Rev Bras Enferm [Internet]. 2017;70(6):1268-76. DOl: http://dx.doi.org/10.1590/0034-7167-2016-0479

Submission: 11-30-2016 Approval: 01-27-2017

\section{ABSTRACT}

Objective: To carry out a cross-cultural adaptation of the Filial Responsibility protocol for use in Brazil with adult child caregivers for elderly parents. Method: A methodological study that included the steps of initial translation, synthesis of translations, back-translation, committee of experts, pre-test, evaluation of psychometric measures and submission to authors. The protocol comprises a qualitative step, closed questions and seven scales: Filial Expectation, Subsidiary Compassion, Caregiver burden, Life Satisfaction, Personal Well-being and Quality of Relationships. Results: The final version in Portuguese was applied, through a pre-test, to a sample of 30 caregivers for elderly parents. In order to verify internal consistency, we used Cronbach's alpha coefficient: Filial Expectation $(\alpha=0.64)$, Filial Duty $(\alpha=0.65)$, Satisfaction with Life $(\alpha=0.75)$, Personal Wellbeing $(\alpha=0.87)$. Final considerations: The Brazilian version presented good conceptual and face equivalence. The results demonstrate that the concepts used in the Canadian protocol are applicable in the Brazilian context.

Descriptors: Validation Studies; Aging; Caregivers; Elderly; Geriatric Nursing.

\section{RESUMO}

Objetivo: Realizar a adaptação transcultural do protocolo Filial Responsibility para uso no Brasil com filhos cuidadores de idosos. Método: Estudo metodológico que compreendeu as etapas de tradução inicial, síntese das traduções, retrotradução, comitê de especialistas, pré-teste, avaliação das medidas psicométricas e submissão aos autores. O protocolo é composto por uma etapa qualitativa, questões fechadas e sete escalas, entre elas: Expectativa Filial, Piedade Filial, Sobrecarga do Cuidador, Satisfação com a Vida, Bem-Estar Pessoal e Qualidade dos Relacionamentos. Resultados: A versão final em português foi aplicada, por meio de pré-teste, a uma amostra de 30 filhos cuidadores de idosos. Para verificar a consistência interna, utilizouse o coeficiente alfa de Cronbach: Expectativa Filial $(\alpha=0,64)$, Dever Filial $(\alpha=0,65)$, Satisfação com a Vida $(\alpha=0,75)$, Índice de Bem-Estar Pessoal $(\alpha=0,87)$. Considerações finais: A versão brasileira apresentou boa equivalência conceitual e semântica. Os resultados demonstram que os conceitos utilizados no protocolo canadense são aplicáveis ao contexto brasileiro.

Descritores: Estudos de Validação; Envelhecimento; Cuidadores; Idoso; Enfermagem Geriátrica.

\section{RESUMEN}

Objetivo: Realizar la adaptación transcultural del protocolo Filial Responsibilitypara uso en Brasil con hijos cuidadores de ancianos. Método: Estudio metodológico que comprendió las etapas de traducción inicial, síntesis de las traducciones, retrotraducción, comité de especialistas, pre test, evaluación de las medidas psicométricas y sumisión a los autores. El protocolo está compuesto por una etapa cualitativa, cuestiones cerradas y siete escalas, entre ellas: Expectativa Filial, Piedad Filial, Sobrecarga del Cuidador, Satisfacción con la Vida, Bien-Estar Personal y Cualidad de las Relaciones. Resultados: La versión final en portugués fue aplicada, por medio de pre test, a una amuestra de 30 hijos cuidadores de ancianos. Para verificar la consistencia interna, se utilizó el coeficiente alfa de Cronbach: Expectativa Filial $(\alpha=0,64)$, Deber Filial $(\alpha=0,65)$, Satisfacción con la Vida $(\alpha=0,75)$, Índice de Bien-Estar Personal $(\alpha=0,87)$. Consideraciones finales: La versión brasileña presentó buena equivalencia conceptual y semántica. Los resultados demuestran que los conceptos utilizados en el protocolo canadiense son aplicables al contexto brasileño.

Descriptores: Estudios de Validación; Envejecimiento; Cuidadores; Anciano; Enfermería Geriátrica.

\section{CORRESPONDING AUTHORＭarines AiresＥ-mail: marynesayres@yahoo.com.br}




\section{INTRODUCTION}

Filial responsibility can be conceptualized as a social and cultural norm and measured through the attitudes and behavior of adult children to care for and support their parents in this pro$\operatorname{cess}^{(1-2)}$. As a social norm, filial responsibility, in addition to the expectation that children should support their elderly parents, reflects a behavior of obligations that define the social role of adult children in relation to the care of their parents during the aging process $^{(3)}$. On the other hand, filial responsibility can also be understood as the right of parents to receive support and care from their children during the aging process ${ }^{(1)}$.

In the various societies, the aging process and care for elderly parents are influenced by culture. In developed countries, especially in Anglo-Saxon societies, the values of individualism and independence are deeply rooted and to a certain extent reduce family obligations of the children to their elderly parents, relegating the care to a responsibility of the State ${ }^{(4)}$. It is seen that in Latin and Asian cultures, children are often given the responsibility of caring for their parents. In Latin society, when the state fails, the family assumes ${ }^{(1)}$. On the other hand, Asian society stands out for its teachings of filial piety, which provide for the respect and care of elderly parents ${ }^{(1)}$.

In Brazil, the Federal Constitution stipulates the parents' duty to assist, raise and educate their minor children; on the other hand, grown children have a duty to help and support their parents in old age, poverty or illness. It also stresses the responsibility of society and the State, together with the family, to support the elderly, preferably in the home ${ }^{(5)}$. These rights are also ensured by the Estatuto do Idoso [Elderly Statute] and the Política Nacional de Saúde da Pessoa Idosa (PNSPI) [National Health Policy for the Elderly] ${ }^{(6-7)}$.

Although it is culturally expected, both in Brazil as well as other Latin and Asian countries, that families take care of their elderly, some factors related to social changes make this process difficult. These include: increasing individualization, migration of young people to cities in search of work, smaller families, and increase in the number of women entering the formal labor market, thereby resulting in fewer people available to care for elderly individuals when needed ${ }^{(4)}$. In order to understand the social changes and their meaning in the families, the responsibility of the children in the care of the elderly parents has been the subject of investigations ${ }^{(1-2)}$.

Based on research that developed and applied a research protocol to analyze filial responsibility in other cultures ${ }^{(2)}$, and through a partnership between Brazilian and Canadian researchers, this study is justified insofar as it adds to the study and has enabled the adaptation of a research protocol for use in Brazil. In this way, it contributes to the development of investigations in different contexts, promoting the integration of scientific information between research nuclei, researchers and their universities. The research is based on a theoretical-methodological framework for cross-cultural adaptation of research tools ${ }^{(8)}$. The use of this protocol in Brazil contributes to the development of research on the theme, analyzed from different perspectives and contexts of life, and addresses the scarcity of research into aspects related to filial responsibility in Brazil. Awareness of the attitudes and behavior of children with regard to elderly parents can generate a basis for action by health professionals and strengthen an extended care approach, considering all aspects in the process of caring for elderly parents.

The present study aims to describe the steps in the process of cross-cultural adaptation of the "Filial Responsibility across cultures: interview schedule" protocol for use in Brazil with people caring for their elderly parents. The protocol comprises two stages: one qualitative and the other quantitative. In the first, open questions cover the children's perceptions of responsibility in the care of their parents. The quantitative step includes closed questions and seven scales in the public domain. Initially, the cross-cultural adaptation of the Qualitative step of the Filial Responsibility protocol ${ }^{(9)}$ was carried out. In the second or quantitative step, the Caregiver Burden Inventory ${ }^{(10)}$ was adapted. The present work describes the complete adaptation process for this instrument.

\section{METHOD}

\section{Ethical aspects}

The project was approved by the Research Ethics Committee of the Hospital de Clínicas de Porto Alegre (HCPA). Authorization was obtained from the Canadian authors to carry out the process of cross-cultural adaptation. The Informed Consent Form was read and signed in duplicate by members of the committee of experts and caregivers.

\section{Study design}

A methodological study was performed based on the theoretical-methodological framework of Cross-cultural Adaptation of Instruments ${ }^{(8)}$. The study was carried out from January to June 2014.

In this work, the following methodological steps were performed: 1) Initial Translation; 2) Synthesis of Translations (T1, T2); 3) Back-translation; 4) Expert Committee; 5) Pre-Test; 6) Submission of the protocol to Canadian researchers; and 7) Evaluation of psychometric measures ${ }^{(8)}$.

\section{Methodological procedures}

\section{Step 1 - Initial Translation}

In this stage, the scales were translated into Portuguese as spoken in Brazil, independently by a medical text translator (T1) and a linguistics teacher (T2).

\section{Step 2 - Synthesis of Translations}

In this phase, the two translations were compared by translators and the researcher, and by consensus, a synthesis-version was prepared in Portuguese.

\section{Step 3 - Back-translation}

The final version in Portuguese (synthesis-version) of the scales was retranslated into the original language by two bilingual translators (R1 and R2) independently (neither had seen the original version of the instrument), and a third translator prepared a consensus for the final back-translation version (R3). 


\section{Step 4 - Expert Committee}

The committee comprised four bilingual specialists with experience in research, teaching and health care for the elderly, as well as the researcher who prepared the synthesis of the initial translations.

The evaluation of the conceptual equivalence, of items and faces between the Portuguese version and the original instrument was performed by the committee members. In this stage, content validation was undertaken by means of a detailed analysis of each item and concept of the scales, then, by consensus, the final version was prepared in Portuguese, which was annexed to the qualitative step of the Filial Responsibility protocol validated in a previous study ${ }^{(9)}$.

\section{Step 5 - Pre-Test}

The final Portuguese version of the Filial Responsibility protocol was applied to a sample of 30 caregivers of elderly people enrolled in a Basic Health Unit (UBS) linked to the Hospital de Clínicas de Porto Alegre (HCPA) and the Federal University of Rio Grande do Sul (UFRGS). The pre-test was applied through a structured interview at home or in the unit. Before starting the interview, the participant was informed of the objectives and encouraged to express any questions regarding the items or issues of the Filial Responsibility protocol. At the end of the interview, an instrument for evaluating understanding of the protocol was applied.

The inclusion criteria were similar to those of the original study: caregiver for at least three months of people aged 60 or over and being involved at least three hours weekly in parental care (in the direct, financial or emotional area). Exclusion criteria were: caregivers under 18 years of age, individuals not located after three attempts at telephone contact at different times and days, or those whose parents had died within the time interval between completing/updating the registry at the unit and collecting data.

\section{Step 6 - Evaluation of psychometric measures}

Reliability was assessed using Cronbach's alpha coefficient to verify the internal consistency of the protocol. Statistical analyses were performed using the Statistical Package for the Social Sciences, version 18.0.

\section{Step 7 - Submission of the protocol to Canadian researchers}

The back-translated version of the Filial Responsibility protocol was sent to the Canadian author for comparison with the original instrument.

\section{Filial Responsibility Protocol}

The protocol is composed of a qualitative and a quantitative stage. In the first stage, open questions are posed about the caregiver's attitudes regarding: the possibility of parental institutionalization and the possibility/occurrence of co-residence; perception about the responsibility of caring for parents; type of support provided and by whom; satisfaction in providing care to parents; expectations about their own aging and being cared for by their children; how caregivers evaluate their relationship with their parents; and about feelings of responsibility for parenting and advice to other caregivers. There is also an open question that allows the caregiver to add some aspect not covered in the instrument. The quantitative step includes closed questions and seven scales in the public domain, namely: Filial Responsibility Expectation Item-Scale ${ }^{(11)}$, Filial Piety Scale ${ }^{(12)}$, Caregiver Burden Inventory ${ }^{(13)}$, Life Satisfaction Scale ${ }^{(14)}$, the Personal Wellbeing Index ${ }^{(15)}$, Relationship Quality Measurement Scale ${ }^{(16)}$, Basic Activities of Daily Life Scale (ADLs) and Instrumental Activities of Daily Living Scales (IADLs) ${ }^{(17-18)}$. Scales are applied to the caregiver to assess care behavior, their activities, and the frequency and time required to perform them.

Closed questions cover the sociodemographic and economic profile of caregivers, aspects related to home arrangement, place of residence and the caregiver's means of traveling to and from their parents' residence, financial support from the caregiver, and emotional support from family and other people in the caregiver's social networks. There are also questions commonly used in gerontological studies to characterize aspects related to health and illness, both for the elderly and their caregivers, about self-assessment of the health of the caregiver, how they evaluate the health of their parents, and also investigates the possibility of dementia or cognitive deficit. It also evaluates how the caregiver feels in relation to his or her family life.

\section{Attitudes of Filial Responsibility}

These were evaluated by the Filial Responsibility Expectation Item-Scale and the Filial Piety Scale.

\section{Filial Responsibility Expectation Item-Scale}

It is the most widely used tool to assess attitudes of filial responsibility and has been validated in North America and in samples with Asians ${ }^{(19-20)}$. The scale is composed of five items that assess aspects related to attitudes such as living close to parents, having room for parents to live with, willingness to care for parents, financial help, living near or visiting parents in old age. The results are analyzed by the continuous sum of the scores: the higher the score, the higher the filial expectation. The scale has a maximum score of 25 points (Question 17).

\section{Filial Piety Scale}

The scale is composed of six items that evaluate the following aspects: helping parents, following their advice, providing financial support, respect, pleasing them, making them happy and keeping in touch with them. The scores are summed, and the higher the score, the greater the filial duty in relation to the care of the elderly parents. The scale has a maximum score of 30 points (Question 18).

\section{Care Behaviors}

The AVDs and IADLs scales were used to evaluate financial support, emotional support, company and visiting. Adult children were asked about what activities the elderly person needed help with, if they helped, how often in the last month and how much time the caregiver spent (Question 20b). Financial support was measured on the basis of responses (yes or no) (Question 21a). Emotional support and company were evaluated based on answers to the following question: How do you feel and meet the needs of emotional support, company and visits to your parents? (Question 20b, 20c). 


\section{Wellbeing Child Caregiver}

This was assessed using the Caregiver Burden Inventory, Life Satisfaction, Personal Wellbeing Index, and Relationship Quality Measurement Scale.

\section{Caregiver Burden Inventory}

It is composed of 24 closed questions that measure the impact of burden on caregivers. It was validated for use with caregivers for elderly persons in Brazil(10). It is evaluated in five subscales: (a) Time Dependence; (b) Developmental; (c) Behavior; (d) Physical Burden; (e) Social Burden; (f) Emotional Burden (Question 22).

\section{Life Satisfaction Scale}

This scale has 10 items and evaluates overall satisfaction with the life of the caregiver, covering both positive and negative aspects. Negative responses were reversed so that the score was always 1 when favorable to the subject. Thus, the higher the score, the more satisfaction with life the caregiver presented (Question 24).

\section{Personal Wellbeing Index}

This scale assesses the level of satisfaction of the child caregiver's regarding their standard of living, health, personal relationships, community living, and financial security (Question 25).

\section{Relationship Quality Measurement Scale}

This scale evaluates three items: how close and affective is the relationship of child caregivers to elderly parents, how enjoyable is the time that child caregivers spend with their parents, and how much do they trust their parents (Question $28 \mathrm{a}, \mathrm{b}, \mathrm{c})$.

\section{Study Scenario}

The scenario of the study was the Basic Health Unit (UBS) of the Hospital de Clínicas de Porto Alegre (HCPA) in Porto Alegre / RS.

\section{RESULTS}

\section{Initial translation}

Two versions were translated independently by a doctor and professor in the health area and a professor of linguistics (T1, T2 respectively), both with English proficiency.

\section{Synthesis of translations}

After the translations were completed, one of the researchers met with the translators to analyze and evaluate any discrepancies between the versions (T1 and T2) and compare them with the original instrument. There were no significant translation difficulties, but the two versions presented translation discrepancies and there was a need to adapt some terms.

\section{Back translation}

In this step, two versions of the back-translated scales were generated for the original language (R1 and R2). Next, the versions were analyzed and compared by the researchers, and a third translator evaluated the two versions, obtaining a back-synthesis synthesis version (R3). The synthesis-version was analyzed and compared by the researchers with the two back-translated versions, noting that there were no discrepancies between the back-translated version and the original instrument.

\section{Evaluation by expert committee}

In this step, face and content validation was performed through a meticulous analysis of each concept and item covered by the instrument. Modifications to the scales were made only with the unanimous approval of all members of the committee, following the same criteria adopted in another study ${ }^{(9)}$.

The committee chose to adapt some words or expressions of the scales according to the local characteristics of the study population, which did not change the purpose of the study. The most significant change was in the Filial Piety Scale.

Filial Piety is a term used in Eastern culture and has a different colloquial sense in our culture. In Chinese culture, it is understood as filial responsibility and means respect for elderly parents. However, the committee considered that in Brazilian culture, this term is not appropriate because it is related to feelings of charity, solidarity, pity, compassion for the suffering of others, present in religious respect and devotion. The committee of specialists also considered that "piety" in our culture represents a sense of "pity", rather than respect and gratitude.

At this stage, the evaluation of a native Canadian teacher residing in Brazil was requested, who considered that the term "filial piety" in the local context needs a greater understanding, on the part of the study population, as respect for parents or devotion to parents. Consequently, "filial piety" was adapted to "filial duty". The concept of filial duty was adopted mainly in consideration of the legislation in force in our country, which legally establishes as the duty of the children to care for the parents during the aging process.

Filial duty was defined in Brazilian culture as respect for parents or devotion to parents, which involves a perception of love and affection, as a relationship of reciprocity and retribution for the care they devoted to their children when they were young. Thus, children feel they have a duty to reciprocate care.

Another aspect the committee considered is that, on both the filial expectation scale and the filial piety scale, there are no issues that address feelings of caring for the parents. These feelings would be present in the Brazilian culture, therefore necessitating the inclusion of such an item in the scale; nevertheless, it was decided not to include this, as it would make a cross-cultural comparison impossible with the original version. Another factor considered was that these aspects would be complemented with the qualitative step in the mixed study.

\section{Pre-test}

At this stage, the Filial Responsibility protocol was applied to a sample of 30 adult child caregivers. The purpose was to evaluate whether they understood the protocol in full and quality of the translation, as well as to verify the practical aspects of its application. In this stage, face validation was performed through the understanding of the questions by a sample of the study population. 
Seven people presented difficulty with only one question of the instrument, and each presented difficulty in different questions. Therefore, this fact was considered a peculiarity of each individual, and not a problem in the translation of the instrument. However all participants expressed difficulty in question 20 to account for the time spent to assist parents in basic and instrumental activities.

In general, the protocol was considered easy to understand by the population and applicable to the local reality, such that there was no need for any changes after the pre-test.

\section{Characterization of the sample}

With regard to the characteristics of the participants, it was found that $24(80 \%)$ were female, $12(40 \%)$ married and nine $(30 \%)$ were single. The mean age was $58.26 \pm 9.78$; they did not have formal employment 19 (63.3\%); and 29 (96.7\%) lived with other people. For the educational level in terms of years of study, the mean was $13.47 \pm 4.46$. In the marital situation of the elderly cared for, $22(73.3 \%)$ were widowers.

\section{Submitting the documents to the authors}

The Canadian researchers evaluated the original version of the protocol and considered that there were no changes in the items and concepts addressed in the instrument that could compromise or alter the study objective.

\section{Psychometric Measures}

The reliability of the scales comprising the protocol was evaluated using Cronbach's alpha coefficient and resulted in an internal consistency for the scales: Filial Expectation $(\alpha=$ $0.64)$, Filial Duty $(\alpha=0.65)$, Satisfaction with Life $(\alpha=0.75)$ and Personal Wellbeing Index $(\alpha=0.87)$.

\section{DISCUSSION}

The Canadian protocol was developed in the English language and later adapted to Mandarin by the researchers of the original work in order to carry out the study with three cultural groups: Canadian caregivers, Chinese caregivers resident in China and Chinese caregivers residing in Canada ${ }^{(1-2)}$. The first experience with the theme in Brazil was the adaptation of the qualitative step ${ }^{(9)}$. The objective of the present investigation was to adapt the protocol as a whole, or that is, including the qualitative and quantitative steps. This adaptation allows researchers to examine the relationship between attitudes and care behavior in the Brazilian context, thereby promoting the integration of scientific information with the international context.

As already underscored, filial responsibility has received considerable attention in the international literature ${ }^{(21)}$. However, in Brazil, the insertion of this subject in research is still recent. Similarly to the original study, filial responsibility was assessed quantitatively (attitudes of filial responsibility and caring behavior) and qualitatively (open questions assessing filial responsibility from the conception of children) ${ }^{(2)}$, which provided a broader understanding of the thematic.

The process of cross-cultural adaptation ${ }^{(8)}$ was shown to be applicable to the local context. The evaluation of several equivalences, the detailing of the steps and the methodological rigor are also highlighted in other studies that used the same reference to adapt instruments ${ }^{(10-22)}$.

It is important to determine whether the concepts used in the original version of the instrument had the same meaning in the new culture, as emphasized by other researchers ${ }^{(8)}$. It was found that most of the concepts used are applicable to the Brazilian context, however, in the present study, there was differentiation in the interpretation of the term "filial piety", which was changed by the expert committee to "filial duty". In China, filial piety means respect and obedience to elderly parents, and is considered a social norm in the country, which is taught to children so that in the future they will care for elderly parents ${ }^{(23-24)}$. Filial duty was conceptualized and validated by the committee for use in Brazilian culture as "respect or devotion to parents", which involves a perception of love, affection, gratitude, relationship of reciprocity and retribution for the care they had received when children.

In relation to the subject under study, it is important to note that international authors ${ }^{(25-26)}$ argue that the literature on filial responsibility reflects a lack of conceptual clarity about which concepts should be measured, as well as inconsistency in how researchers should operationalize and measure such constructs. Similar to the present study, during the adaptation of the Caregiver Burden Inventory for use in Brazil, it was also pointed out that the existence of cultural differences between countries may mean that the instrument being adapted lacks dimensions present in the target-culture. This should also be investigated, as was the case in the financial field, which was not addressed in the original version ${ }^{(10)}$. In the present study, it was also identified that, both in the filial expectation scale and in filial duty, the questions about caring for parents should include aspects present in the Brazilian culture. However, the committee chose not to include these because it would render cross-cultural comparison with the original version impossible and because these aspects would be covered in the qualitative stage of the study.

In the initial translation stage, the methodological framework used suggests that at least two independent translations of the instrument from the original language (English) into the target language (Portuguese), as well as other studies of the research group to which the researcher is linked, proved to be effective ${ }^{(9-10,22)}$. The choice of the translators at this stage, being a professional in the area and another in the linguistic sciences, was of extreme importance for the quality of the translation, which is in line with other studies that highlight the influence of the profile of the translators in the adaptation process ${ }^{(9,27)}$.

In relation to the synthesis-version of the translations (T1 and T2), a joint revision of the versions is recommended ${ }^{(8)}$. In the present study, this strategy enabled a discussion between the researcher and translators regarding discrepancies between the translated version in a literal sense, and another with a health professional with a more flexible translation in certain aspects, considering the subjects' understanding and the terms that would best suit the local context.

The back-translation examines whether the translated version accurately reflects the content of the original instrument, as well as identifying conceptual inconsistencies or errors in 
translation ${ }^{(28)}$. In the present study, the back-translation of the synthesis-version in Portuguese was performed independently by two bilingual translators who were blinded to the initial translation, as recommended in the theoretical framework of cross-cultural adaptation ${ }^{(8)}$. This criterion was fundamental to maintain a face equivalence and did not alter the objectives of the study, which was also highlighted by other studies ${ }^{(9-10,22)}$. Not knowing the study objectives at this stage prevents translators from using prior knowledge to correct eventual errors during back translation. In addition, the participation of a third bilingual translator, who formally evaluated the equivalence between the back-translations and the original instrument, was also added and the synthesis-version was prepared in English. This approach is also recommended in the theoretical framework of cross-cultural adaptation ${ }^{(8)}$. Likewise, other studies included the evaluation by a professional third party in order to compare the versions with the original instrument with regard to maintenance of equivalence ${ }^{(9,27)}$.

An important aspect that contributed to the adaptation of the protocol was the multidisciplinary composition of the expert committee, which brought together professionals related to teaching, research and assistance in the area of Geriatric health, who were bilingual, and had previous experience in both the country in which the study originated and in countries with an oriental culture. Other research has reinforced the importance of the expert committee composition to ensure peers that are bilingual and have experience in the culture of origin. Thus, they can obtain a better conceptual and face equivalence in the construction of the new version of the instrument, besides identifying possible errors during the translation and back-translation process $^{(9-10,22)}$. In the present study, this integration allowed an articulation between different specific knowledge and contributed to the elaboration of a final version of the protocol that is adapted to the local reality. It is noteworthy that at this stage the committee requested the participation of a Canadian professor of medicine residing in Brazil, who contributed to the translation and comprehension of certain items addressed in the protocol.

The consensus evaluation by the committee in the present study allowed all the members to collaborate, exposing their difficulties, questions and suggestions about the protocol and concepts addressed, in order to compose a version adapted to the local reality. In addition, when no consensus was reached, as in the term "filial piety", the evaluation of a native teacher from Canada with experience in the area of study was solicited to help the committee reach a consensus.

Similar to other investigations already conducted by the researcher and research group, content and face validity was assessed through a committee of experts and application of the protocol to a sample of the study population during the pretest ${ }^{(9,22)}$. At this stage, it was possible to suggest the removal, addition or modification of items ${ }^{(8)}$, which were not applicable in the present study. It was found that, because this was the adaptation of a protocol, the evaluation of content and face validity was a criterion used to assess the quality of the items that compose the protocol. In addition to defining with precision, the reliability of the concepts measured and that which it is proposed to measure, i.e. the phenomenon studied. According to the criteria established in the COSMIN Manual, content validity allows a detailed evaluation of the relevance and comprehensiveness of the items that make up the instrument ${ }^{(29)}$. It is also added that, during the content and face validation by the committee, it was possible to identify concepts that are inappropriate to the local reality, as presented in the results.

The methodology used suggests that the pre-test stage should be performed by applying it to a sample of the population under study, with the purpose of identifying difficult to understand words or questions, evaluating their acceptability and commenting on the instrument in general. In the present study, the pre-test was performed by applying it to a sample of child caregivers, with the objective of evaluating whether the study population understood the items, besides confirming if the instrument was applicable to a new reality. In this way, it was possible to analyze the items and their suitability to the local context, and this stage was extremely relevant for the composition of the final version of the protocol. It is noteworthy that, during the interviews, there were child caregivers who presented greater difficulty in understanding the issues than others, and this factor may be related to their level of education, as well as comprehension difficulties due to age; in addition, the protocol should be considered extensive and may cause discomfort and fatigue to the caregiver.

The submission stage was important for the Canadian researcher to analyze each of the items of the original protocol with the back-translated version in order to verify if during the cross-cultural adaptation process there were modifications as to its original format, such as withdrawal of some item or addition of others that could compromise the objectives of the study. Thus, at the end of this stage, it was concluded that the final version presented equivalence in relation to the original. Furthermore, in the present study, it should be considered that the protocol covers other scales by different authors. This is a fundamental step so that the instrument can be used reliably in the local context, since, even though the equivalence has been assured between the original version and the one modified by cross-cultural adaptation, the fact that modifications have been made to the instrument and that it is being applied in a different scenario may alter its psychometric properties ${ }^{(8)}$.

Despite the cross-cultural adaptation process, the methodological rigor followed in the study and the rigorous evaluation by the expert committee, the results of the internal consistency are inferior to that considered to be ideal (Filial Expectations $\alpha=$ 0.64 , filial duty $\alpha=0.65$ ) which could be due to cultural issues between the countries. It should also be considered that both Filial Expectation and Filial Duty measures are used together in the measurement of filial responsibility. In addition, they are old scales, besides the sample size being relatively small for the accomplishment of the validation. In the end, we chose to maintain the items of the original scale, considering that the scales are inserted in a protocol and will not be used in individual studies.

Authors in the cross-cultural adaptation field point out that values below 0.7 can be expected due to the diversity of that which is being measured ${ }^{(8)}$. As already underscored, the theme of filial responsibility is relatively new in Brazil, and also in 
the international context there is a difficulty in measuring the constructs that evaluate it, given the influence of cultural specificities. Regarding the use of the Filial Responsibility protocol in other studies, Cronbach's alpha ranged between 0.69 and $0.83^{(2)}$. On the other hand, the Life Satisfaction scales $(\alpha=0.75)$ and Personal Wellbeing Index $(\alpha=0.87)$ presented Cronbach's alpha within the expected standards.

\section{Study limitations}

Considering that the present study proposed to perform the cross-cultural adaptation of a broad research protocol, the sample size was relatively small for validation. In addition, the nature of the scales used to measure attitudes of filial responsibility, or that is, the constructs evaluated, may not allow a specific measurement of filial responsibility, besides being very old scales. Moreover, these scales were validated as representing the normative dimensions of filial responsibility in the cultures studied (three distinct cultural groups), that is, the results reflect the notion defended as part of the cultural norm of each group under study. In addition, the study was carried out in a sample with specific characteristics in Rio Grande do Sul State, with a socioeconomic and educational level higher than those of other national studies, without considering that the state has several regions with different beliefs, customs and values and diverse cultures due to immigration.

\section{Contribution to Nursing, health or public policy}

The study promotes the implementation of public policies and welfare practices, in order to include this group in the care process. With regard to nursing care, knowing the attitudes of filial responsibility and analyzing caregiving behavior based on instrumental support, emotional support, companionship and financial support, and broadly assessing the well-being of the caregiver are important during the nurse's evaluation for developing a plan of care. It also contributes to the decision making of the children, regarding the process of caring for the elderly, the possibility of institutionalization, or the fact that the elderly live alone.

In addition, the nurse must establish a therapeutic bond with these families, seeking to identify the needs of both the elderly and the caregiver, to trace care strategies that provide stress relief, organization and systematization of the care, support and reception of the complaints by these people.

The protocol can be applied in other national contexts so that different family matrices and cultural diversities can be identified, considering the extension of the country and the processes of immigration and emigration that occurred in the various Brazilian regions. The results of research into the responsibility of the children in caring for parents can be used in varied scenarios of nursing practice when experiencing different attitudes and behaviors of caring, that require the professionals provide specific interventions adapted to each reality.

\section{FINAL CONSIDERATIONS}

The use of the steps discussed in this study allowed us to maintain the conceptual equivalence of the original protocol and the face equivalence in the local context of the study, preserving the objective of the baseline study and the quality of protocol information. The differential of the present study was to use a theoretical-methodological framework of crosscultural adaptation, used basically to validate scales in the cross-cultural adaptation of a broad research protocol. The use of a broad protocol (open and closed questions and also scales) allowed the measurement of attitudes regarding filial responsibility based on two measures (expectation and filial duty), to analyze care behaviors based on instrumental support, emotional support, company and financial support, and to assess the welfare of the caregiver in an extended way, using the complementary open questions.

The filial responsibility, already studied in the international context, is a recent theme in Brazil. Therefore, with the adaptation of this protocol, it is possible to insert it in the context of the Brazilian research and to encourage the use of the Filial Responsibility protocol by other Brazilian researchers.

The Brazilian version presented a good conceptual and face equivalence, and the results demonstrated that the concepts and items used in the protocol are applicable to the Brazilian context.

\section{FUNDING}

This study was performed with the financial support of the Conselho Nacional de Desenvolvimento Científico e Tecnológico, via Project nº476470/2013-7 and from a Research Grant from the Hospital de Clínicas de Porto Alegre.

\section{ACKNOWLEDGEMENTS}

Ana Cláudia Fuhrmann and Kamila Dellamora Raubustt, scholarship students of Scientific Initiation, for their help in the data collection.

\section{REFERENCES}

1. Chappell NL, Funk L. Filial Caregivers; diasporic chinese compared with homeland and hostland caregivers. J Cross Cult Gerontol[Internet] 2011[cited 2015 Jan 21];26(4):315-29. Available from: http://dx.doi.org/10.1007/s10823-011-9154-x

2. Chappell NL, Funk L. Filial responsibility: does it matter for care-giving behaviours? Ageing Soc [Internet]. 2012 [cited 2012 Mar 25];32(7):1128-46. Available from: http://dx.doi.org/10.1017/s0144686x11000821

3. Gans D, Silverstein M. Norms of Filial Responsibility for Aging Parents across Time and Generations. J Marriage Fam[Internet]. 2006[cited 2015 Jan 21];68(4):961-76. Available from: http://dx.doi.org/10.1111/j.1741-3737.2006.00307.x 
4. World Health Organization. Envelhecimento ativo: uma política de saúde. Brasília (DF): Organização Pan-Americana de Saúde; 2005. 62p.

5. Brasil. Constituição da República Federativa do Brasil. Brasília (DF): Senado Federal; 1988.

6. Brasil. Senado Federal. Estatuto do Idoso. Brasília (DF): Senado Federal; 2003.

7. Brasil. Ministério da Saúde. Portaria n 2.528, de 19 de outubro de 2006. Aprova a Política Nacional de Saúde da Pessoa Idosa. Brasília (DF): Ministério da Saúde; 2006.

8. Beaton D, Bombardier C, Guillemin F, Ferraz MB. Recommendations for the cross-cultural adaptation of the DASH \& QuickDASH outcome measures. Toronto: Institute for Work \& Health; 2007.

9. Aires M, Weissheimer AM, Rosset I, Oliveira FA, Morais EP, Paskulin LM. Transcultural adaptation of the filial responsibility interview schedule for Brazil. Int Nurs Rev[Internet]. 2012[cited 2015 Jan 21];59(2):266-73. Available from: http://dx.doi. $\operatorname{org} / 10.1111 / \mathrm{j} .1466-7657.2011 .00940 . x$

10. Valer DB, Aires M, Fengler FL, Paskulin LMG. Adaptation and validation of the Caregiver Burden Inventory for use with caregivers of elderly individuals. Rev Latino-Am Enfermagem [Internet]. 2015[cited 2015 Jan 17];23(1):130-8.Available from: http://dx.doi. org/10.1590/0104-1169.3357.2534

11. Seelbach WC, Sauer WJ. Filial responsibility expectations and morale among aged parents. J Gerontol[Internet]. 1977 [cited 2015 Jan 18];17(6):492-9. Available from: http://dx.doi.org/10.1093/geront/17.6.492

12. Gallois C, Giles H, Ota H, Pierson HD, Ng SH, Lim TS, Maher J, et al. Intergenerational communication across the Pacific Rim: the impact of filial piety. Paper presented at the annual conference of the International Association of Cross-Cultural Psychology, Montreal (CA); 1961.

13. Novak M, Guest C. Application of a Multidimensional Caregiver Burden Inventory. J Gerontol[Internet]. 1989 [cited 2015 Jan 18];29(6):798-803. Available from: http://dx.doi.org/10.1093/geront/29.6.798

14. Neugarten BL, Havighurst RJ, Tobin SS. The measurement of life satisfaction. J Gerontol [Internet]. 1961 [cited 2015 Jan 17];16(2):134-43. Available from: http://dx.doi.org/10.1093/geronj/16.2.134

15. Lau ALD, Cummins RA, McPherson W. An Investigation into the cross-cultural equivalence of the Personal Wellbeing Index. Soc Indic Res[Internet]. 2005[cited 2015 Jan 18];72(3):403-430. Available from: http://dx.doi.org/10.1007/s11205-004-0561-z

16. Lee YR, Sung KT. Cultural differences in caregiving motivations for demented parents: Korean caregivers versus American caregivers. Int J Aging Hum Dev [Internet]. 1997[cited 2015 Feb 17];44(2):115-27. Available from: http://dx.doi.org/10.2190/ BLY5-07M1-6VVY-XJMX

17. Katz S, Ford AB, Moskowitz RW, Jackson BA, Jaffe MW. Studies of Illness in the Aged. The Index of ADL: a standardized measure of biological and psychosocial function. JAMA [Internet]. 1963[cited 2015 Feb 13];185(12):914-9. Available from: http://dx.doi. org/10.1001/jama.1963.03060120024016

18. Lawton MP, Brody E. Assessment of older people: self-maintaining and instrumental activities of daily living. J Gerontol[Internet]. 1969[cited 2015 Feb 13];9(3):179-86. Available from: http://dx.doi.org/10.1093/geront/9.3_Part_1.179

19. Kim JS, Lee EH. Cultural and noncultural predictors of health outcomes in Korean daughter and daughter-in-law caregivers. Public Health Nurs[Internet]. 2003[cited 2015 Feb 8];20(2):111-9. Available from: http://dx.doi.org/10.1046/j.1525-1446.2003.20205.x

20. Stein $\mathrm{CH}$, Wemmerus VA, Ward M, Gaines ME, Freeberg AL, Jewell TC. 'Because they're my parents': an intergenerational study of felt obligations and parental caregiving. J Marriage Fam [Internet]. 1998[cited 2015 Feb12];60(3):611-22. Available from: http:// dx.doi.org/10.2307/353532

21. Funk L. The interpretive dynamics of filial and collective responsibility for elderly people. Can Rev Sociol [Internet]. 2010[cited 2015 Feb 14];47(1):71-92. Available from: http://dx.doi.org/.10.1111/j.1755-618X.2010.01223.x

22. Paskulin LMG, Aires M, Valer DB, Morais EP, Freitas IBA. Adaptation of an instrument to measure health literacy of older people. Acta Paul Enferm[Internet]. 2011 [cited 2015 Feb 5];24(2):271-7. Available from: http://dx.doi.org/10.1590/S0103-21002011000200018

23. Cheung C, Kwan AY, Ng SH. Impacts of filial piety on preference for kinship versus public care. J Community Psychol[Internet]. 2006[cited 2015 Feb 5];34(5):617-34. Available from: http://dx.doi.org/10.1002/jcop.20118

24. Del Corso AR, Lanz M. Felt obligation and the family life cycle: A study on intergenerational relationships. Int J Psychol[Internet]. 2013[cited 2015 Feb 3];48(6):1196-200. Available from: http://dx.doi.org/10.1080/00207594.2012.725131

25. Jones PS, Lee JW, Zhang XE. Clarifying and measuring filial concepts across five cultural groups. Res Nurs Health[Internet]. 2011[cited 2015 Feb 5];4(4):310-26. Available from: http://dx.doi.org/10.1002/nur.20444

26. Kim BK, Li LC, Ng GF. The Asian American Values Scale--Multidimensional: development, reliability, and validity. Cult Divers Ethnic Minor Psychol[Internet]. 2005[cited 2015 Feb 18];11(3):187-201. Available from: http://dx.doi.org/10.1037/1099-9809.11.3.187

27. Paixão Júnior CM, Reichenheim ME, Moraes CL, Coutinho ESF, Veras RP. Cross-cultural adaptation to Brazil of the instrument Caregiver Abuse Screen (CASE) for detection of abuse of the elderly by caregivers. Cad Saúde Publica[Internet]. 2007 [cited 2015 Feb 3];23(9):2013-22. Available from: http://dx.doi.org/10.1590/S0102-311X2007000900010 
28. Hora EC, Sousa RMC. Cross-cultural adaptation of the instrument. Rev Latino-Am Enfermagem[Internet]. 2009 [cited 2015 Feb 8];17(4):541-47. Available from: http://dx.doi.org/10.1186/1471-2288-10-13

29. Mokkink LB, Terwee CB, Patrick DL, Alonso J, Stratford PW, Knol DL, et al. COSMIN checklist manual [Internet]. Institute for Health and Care Research, Amsterdam (NL); 2012[cited 2015 Feb 8]. Available from: http://www.cosmin.nl/images/upload/files/ COSMIN\%20checklist \%20manual\%20v9.pdf 